\title{
The effect of osmotic dehydration pretreatment with sweeteners on the quality of dried aronia berries
}

\author{
Suin Bae ${ }^{1}$, Ji-Young Choi ${ }^{1}$, Hyeon-Jeong Lee ${ }^{2}$, Jiyoon Kim ${ }^{1}$, Kwang-Deog Moon ${ }^{1,3 *}$ \\ ${ }^{1}$ School of Food Science and Technology, Kyungpook National University, Daegu 41566, Korea \\ ${ }^{2}$ Dalseong County Office, Agricultural Technology Center, Rural Guidance Division, Daegu 42974, Korea \\ ${ }^{3}$ Food and Bio-industry Research Institute, Kyungpook National University, Daegu 41566, Korea
}

\begin{abstract}
Aronia (Aronia melanocarpa) berries are rich in polyphenols. However, they are extremely astringent, which reduces their commercial viability. This study suggests a treatment method to produce more commercial aronia products. In this method, the berries were pretreated with osmotic dehydration and then dried with hot air or lyophilized to reduce their astringency. Sucrose, glucose, and xylitol were used as the pretreatment solutions. The products were prepared and grouped as follows: raw aronia (CON), freeze-dried (FD), osmo-dehydrated using sucrose solution and freeze-dried (FDS), osmo-dehydrated using glucose solution and freeze-dried (FDG), osmo-dehydrated using xylitol solution and freeze-dried (FDX), hot-air-dried (HD), osmo-dehydrated using sucrose solution and hot-air-dried (HDS), osmo-dehydrated using glucose solution and hot-air-dried (HDG), and osmo-dehydrated using xylitol solution and hot-air-dried (HDX). Water loss was highest in aronia berries that were osmo-dehydrated using sucrose solution $(16.36 \%)$, followed by berries that were dehydrated using glucose solution $(14.26 \%)$, and those that were osmo-dehydrated using xylitol solution (12.83\%). Moisture contents and total soluble solid contents of the FD products were 3.83-7.45\% and 6,908.47 ${ }^{\circ}$ Brix, respectively. FDS and FDX showed relatively high phenolic compound contents and antioxidant activities. FDG and FDS showed better texture and redness. FDS received the highest score for sweetness (5.07) and overall preference (5.13). Hence, FDS proved to be the most appropriate pretreatment, because it allows a better control of the moisture content and maintenance of their appearance and texture, with a relatively low reduction of their phenolic contents. Hence, it affords better preservation efficiency to aronia products.
\end{abstract}

Key words : Aronia melanocarpa, osmotic dehydration, dried fruit product, sweetener, physicochemical propert

\section{Introduction}

Aronia (Aronia melanocarpa), also called black chokeberry, belongs to the Rosaceae family and is native to North America (Hardin, 1973). In Korea, aronia is being cultivated since 2007 (Choi et al., 2015). It is rich in phenolic substances, including flavonoids, anthocyanins, and proanthocyanidins (Oszmianski and Wojdylo, 2005). These compounds have high antioxidant activity and are known to be effective in preventing cardiovascular diseases, hyper- lipidemia, hypertension, and diabetes (Sidor et al., 2019). However, proanthocyanidins, a type of condensed tannin, consist of flavan-3-ol as the oligomer and bind to saliva, causing astringency (Soares et al., 2017; Xie and Dixon, 2005). As a result, aronia consumption in Korea is less than its production. Therefore, it is necessary to develop a new product that fits the taste of customers to resolve this concern. To achieve this goal, an appropriate strategy should be developed to reduce the astringency of raw aronia.

Vegetables and fruits are prone to rapid spoilage because

\footnotetext{
*Corresponding author. E-mail : kdmoon@knu.ac.kr, Phone :+82-53-950-5773, Fax : +82-53-950-6772

Received 07 May 2020; Revised 19 June 2020; Accepted 22 June 2020.

Copyright (c) The Korean Society of Food Preservation.

This is an Open Access article distributed under the terms of the Creative Commons Attribution Non-Commercial License (http://creativecommons.org/licenses/by-nc/4.0) which permits unrestricted non-commercial use, distribution, and reproduction in any medium, provided the original work is properly cited.
} 
of their high moisture contents (MC). Therefore, they are subjected to a drying process to achieve their long-term storage (Dev and Raghavan, 2012). Osmotic dehydration is a simple, low-cost drying pretreatment, which can increase the drying efficiency (Ahmed et al., 2016). In this pretreatment, the product is infiltrated with a highly concentrated solution of an osmotically active solute (e.g., salt, sugar, and polyol) to reduce the MC through osmosis (Lewicki and Lenart, 2006).

Although the drying kinetics of osmotic dehydration has been investigated, studies on the components and physicochemical properties of the resulting products are scarce. Therefore, the feasibility of drying processes that can be applied to aronia should be first explored. In addition, while the properties of the aronia extract or the characteristics of foods made with aronia powder or juice have been well-researched (Hwang and Lee, 2013), only a few studies have investigated the properties of aronia as a standalone product. The purpose of this study was to evaluate a potential pretreatment process to obtain new dried aronia food products that minimizes the reduction of functional substances such as phenolic compounds and antioxidants, but improves the sensory attributes through osmotic dehydration pretreatment using various sweeteners.

\section{Materials and methods}

\section{Materials}

Aronia (A. melanocarpa) was cultivated in a farm in Sangju-si, Kyungsangbuk-do, Korea, and was still frozen upon purchase. After removing the stems, aronia berries were sorted by weight $(1.20$ and $0.20 \mathrm{~g})$ and thawed for 90 min before pretreatment. Sucrose $(100 \%$; CJ, Incheon, Korea), glucose $(99.5 \%$ with $0.5 \%$ dextrin; Hwami, Incheon, Korea), and xylitol (100\%; Roquette, Lestrem, France) were used as sweeteners. These sweeteners are classified as a disaccharide, monosaccharide, and sugar alcohol, respectively; hence, they have different structures.

\section{Osmotic dehydration pretreatment}

Sucrose, glucose, and xylitol were used to prepare highly concentrated osmotic solutions (60 ${ }^{\circ}$ Brix) to achieve the same sweetness values. Aronia berries were placed in each solution in a ratio of 1:4 (w:w) and then subjected to osmotic dehydration at $40^{\circ} \mathrm{C}$ for $3 \mathrm{~h}$ by applying $40-\mathrm{kHz}$ ultrasonic waves using an ultrasonic cleaner (DH.WUC. D22H, Daihan-Sci, Wonju, Korea). After pretreatment, osmo-dehydrated aronia berries were washed with distilled water (DW) for $10 \mathrm{sec}$ and wiped with a tissue paper to remove any water from the surface.

\section{Drying}

Hot-air drying was conducted at $50^{\circ} \mathrm{C}$ for $57 \mathrm{~h}$ using a dryer (BL950903, Gumbok Stoke Co., Ltd., Seoul, Korea). Freeze-drying was conducted for 4 days using a lyophilizer (LP20-XX, Ilshin Biobase Co., Ltd., Dongducheon, Korea). To determine the optimum drying time for aronia berries, the conditions with the highest overall preference were selected through a preliminary experiment, and the drying time was set. The samples were grouped as follows: raw aronia $(\mathrm{CON})$, freeze-dried aronia (FD), aronia osmodehydrated using sucrose and FDs, aronia osmo-dehydrated using glucose and freeze-dried (FDG), osmo-dehydrated using xylitol and freeze-dried (FDX), hot-air-dried aronia (HD), aronia osmo-dehydrated using sucrose and hot-airdried (HDS), aronia osmo-dehydrated using glucose and hot-air-dried (HDG), and aronia osmo-dehydrated using xylitol and hot-air-dried (HDX).

\section{Moisture content}

The moisture content (MC) of dried aronia was measured gravimetrically by drying in an oven (JSOF-150, JS Research, Inc., Gongju, Korea) at $103^{\circ} \mathrm{C}$ for $40 \mathrm{~h}$, which was calculated by the following equation:

$$
\mathrm{MC}=(\mathrm{w} 0-\mathrm{wS}) / \mathrm{w} 0 \times 100(\%)
$$

where w0 is the initial weight of aronia and wS is the weight of oven-dried aronia.

\section{Total soluble solids and $\mathrm{pH}$}

Here, $5 \mathrm{~g}$ of the aronia product was blended with $45 \mathrm{~mL}$ of DW using a hand blender (HR1604, Artreal Huiyang Manufacturing Ltd., Hui Zhou, China) for $30 \mathrm{sec}$ and then filtered using Whatman No.4 filter paper. The total soluble solid content was measured using a refractometer (Master-a, Atago Co., Tokyo, Japan). The $\mathrm{pH}$ was measured using a pH meter (Orion 3 Star, Thermo Electron Co., Waltham, 
MA, USA).

\section{Free sugar content}

After pretreatment in the same manner as before $\mathrm{pH}$ was measured, the sample was refiltered using a $0.45 \mathrm{~m}$ membrane filter, and the obtained filtrate was used for free-sugar analysis. The free-sugar content was measured by high-performance liquid chromatography (HPLC; 2695, Alliance, Waters Co., Milford, MA, USA), and a Sugar-Pak I column $(6.5 \mathrm{~mm} \times 300 \mathrm{~mm}$; Waters Co. $)$ was used. The operating conditions were as follows: mobile phase, $0.01 \mathrm{M}$ CaEDTA (50 mg/L DW); injection volume, $20 \mu \mathrm{L}$; column temperature, $90^{\circ} \mathrm{C}$; flow rate, $0.5 \mathrm{~mL} / \mathrm{min}$; detection mode, refractive index.

\section{Aronia methanol extract}

Aronia methanol extract (AME) was prepared using a previously described method (Kim et al., 2016) with slight modifications. First, $5 \mathrm{~g}$ of aronia was cut into pieces, and $45 \mathrm{~mL}$ of $80 \%$ methanol solution was added. This mixture was shaken at $120 \mathrm{rpm}$ at $30^{\circ} \mathrm{C}$ for $26 \mathrm{~h}$ in a shaking incubator (JSSI-300C, JSR, Gongju, Korea), and then the mixture was filtered (Whatman No.4 filter paper). The filtrate was concentrated using a rotary vacuum concentrator, methanol was completely removed using an oven at $70{ }^{\circ} \mathrm{C}$, and the concentrate was diluted with $80 \%$ methanol at $100 \mathrm{mg} / \mathrm{mL}$ of the concentrate.

\section{Total phenolic content}

The total phenolic content (TPC) was determined using the Folin-Ciocalteu method (Benvenuti et al., 2004) with slight modifications. A mixture of $1 \mathrm{~mL}$ of AME and $1 \mathrm{~mL}$ of $50 \%$ Folin-Ciocalteu reagent was prepared and left in the dark for $15 \mathrm{~min}$. Afterward, $1 \mathrm{~mL}$ of $10 \%$ sodium carbonate solution was added, and the mixture was left for $1 \mathrm{~h}$ before reading the absorbance values at $750 \mathrm{~nm}$ using an Evolution 201 UV-visible spectrophotometer (Thermo Fisher Scientific, Brooklyn, NY, USA). Gallic acid was used as the standard, and the results were expressed as $\mathrm{mg}$ of gallic acid equivalents (GAE)/100 $\mathrm{g}$ of aronia dry weight (dw).

\section{Anthocyanin content}

The anthocyanin content (AC) was assayed using the $\mathrm{pH}$ differential method (Giusti and Re, 2001). The AME was diluted with $0.025 \mathrm{M}$ potassium chloride buffer ( $\mathrm{pH} 1.0$ ), incubated for $15 \mathrm{~min}$, and then the spectrophotometric absorbance at 515 and $700 \mathrm{~nm}$ was recorded. The dilution factor was set so that the absorbance value was 8.0-1.0 at $515 \mathrm{~nm}$. Likewise, $0.4 \mathrm{M}$ sodium acetate buffer ( $\mathrm{pH} 4.5$ ) was used in the same way as the $\mathrm{pH}$ buffer, and the $\mathrm{AC}$ was calculated as follows:

$$
A C=\left(A_{515 \mathrm{~nm}}-A_{700 \mathrm{~nm}}\right)_{\mathrm{pH} 1.0}-\left(A_{515 \mathrm{~nm}}-A_{700 \mathrm{~nm}}\right)_{\mathrm{pH} 4.5} ;
$$

where $\mathrm{A}_{515} \mathrm{~nm}=$ absorbanceat $515 \mathrm{~nm}$;

$\mathrm{A}_{700} \mathrm{~nm}=$ absorbanceat $700 \mathrm{~nm}$.

\section{Proanthocyanidin content}

The proanthocyanidin content (PC) was evaluated using Broadhurst and Jones' method (1978) with slight modifications. An aliquot $(0.3 \mathrm{~mL})$ of AME was mixed with $1.8 \mathrm{~mL}$ of $4 \%$ vanillin-methanol solution and 0.9 $\mathrm{mL}$ of $32 \% \mathrm{HCl}$, and the mixture was incubated in the dark for $15 \mathrm{~min}$. The absorbance was measured at 500 nm. The standard was (+)-catechin (CAT), and the results were expressed as $\mathrm{mg}$ of $\mathrm{CAT} / 100 \mathrm{~g} \mathrm{dw}$.

\section{Antioxidant activity}

The fluorescence recovery after photobleaching (FRAP) assay was conducted by using Benzie and Strain's (1996) method. Acetate buffer (300 mM, pH 3.6), $10 \mathrm{mM}$ 2,4,6-Tri(2-pyridyl)-s-triazine, and $20 \mathrm{mM} \mathrm{FeCl}_{3} \cdot 6 \mathrm{H}_{2} \mathrm{O}$ (10:1:1,v:v:v)were mixed immediately before the experimentand incubated at $35^{\circ} \mathrm{C}$ for $10 \mathrm{~min}$. An aliquot $(1.8$ $\mathrm{mL}$ ) of this mixture was added to $0.2 \mathrm{~mL}$ AME. After incubating for $30 \mathrm{~min}$, the absorbance was measured at $590 \mathrm{~nm}$. The ABTS was measured as previously described by $\mathrm{Re}$ et al. (1999). A mixture of $2.45 \mathrm{mM}$ potassium persulfate solution and $7 \mathrm{mM}$ ABTS solution (1:2, v:v) was left for $16 \mathrm{~h}$, and then diluted with ethanol to obtain absorbance of $0.70 \pm 0.02$ at $734 \mathrm{~nm}$. The AME $(20$ L) was mixed with $2 \mathrm{~mL}$ of the activated solution and incubated in the dark for $6 \mathrm{~min}$ before measuring the absorbance at $734 \mathrm{~nm}$. For both AA assays, Trolox served as the standard, and the results were expressed as $\mathrm{mmoL}$ of Trolox equivalents (TE)/100 g dw. 


\section{Texture}

Strength and hardness were measured by a rheometer (Compac-100II, Sun Scientific Co., Tokyo, Japan). The probe was set to penetrate $8 \%$ of the sample's height at a speed of $100 \mathrm{~mm} / \mathrm{min}$. The test was repeated five times per sample.

\section{Color}

The aronia product was blended using a hand blender (SU07843-12003, KCC-REI-PCE-HR1600, Philips, Amsterdam, the Netherlands). Color parameters, including $\mathrm{L}^{*}$ (lightness), $\mathrm{a}^{*}$ (redness), and $\mathrm{b}^{*}$ (yellowness), were directly recorded using a colorimeter (CR-400, Konica Minolta, Tokyo, Japan). Before measuring, the colorimeter was calibrated against a standard white tile. Measurements were repeated 15 times per sample.

\section{Sensory evaluation}

Fifteen trained panel members evaluated the appearance, color, texture, chewiness, sweetness, sourness, astringency, and overall preference on a 7-point scale. Astringency was measured through an objective evaluation $(1=$ little astringency; $7=$ extreme astringency), while the other attributes were measured through preference ratings $(1=$ very bad; $7=$ very good). A product that received a score of 3 points or less was considered commercially unviable. This sensory evaluation was performed with the approval of the Kyungpook National University Industry Foundation (Approval number: 2019-0052).

\section{Statistical analysis}

The experiments were repeated three or more times, and the results were expressed as the mean standard deviation. ANOVA was performed using the SPSS software package (version 25.0; SPSS, Inc., Chicago, IL, USA). Significant differences were determined using Duncan's multiple range test $(\mathrm{p}<0.05)$.

\section{Results and discussion}

\section{Moisture content, total soluble solids, and $\mathrm{pH}$}

The MC, TSS, and $\mathrm{pH}$ data are presented in Table 1. The MC of raw aronia (CON) was $83.22 \%$. The MC range of the $\mathrm{FD}$ was $3.83 \%, 7.45 \%$, which was noticeably lower than that of HD. Mishra et al. (2015) prepared dried papaya cubes by infrared drying at $2 \mathrm{kGy}$, followed by their blanching and osmotic dehydration pretreatment. The dried cubes had an MC of 38\%. Furthermore, no bacteria, yeast, mold, or Staphylococcus were detected after the cubes were stored for 60 days. We followed the same method for drying the aronia berries. We noticed that except for CON, HD, and HDS aronia berries, the other six products (FD, FDS, FDG, FDX, HDG, and HDX) seem to be safe from microorganisms. The MC of the pretreated aronia berries decreased in the order of CON, followed by the berries osmo-dehydrated with sucrose, glucose, and xylitol for both drying methods. This tendency may be explained by the proportion of sweetener infiltration and loss of moisture in the aronia berries during osmotic dehydration. The TSS range was 6,908.47 ${ }^{\circ}$ Brix for the FD samples and 3.705.87 ${ }^{\circ}$ Brix for the HD samples. Moreover, the FD samples showed generally higher $\mathrm{pH}$ than the $\mathrm{HD}$ samples; $\mathrm{CON}$ had the highest $\mathrm{pH}$. This trend of $\mathrm{pH}$ is thought to result from freeze-drying that maintains the characteristics of the samples better than hot-air-drying. Glucose-treated products showed the lowest $\mathrm{pH}$, irrespective of the drying

Table 1. Moisture content, total soluble solids, and pH of dried aronia products

\begin{tabular}{cccc}
\hline Sample $^{1)}$ & $\begin{array}{c}\text { Moisture } \\
\text { content (\%) }\end{array}$ & $\begin{array}{c}\text { Total soluble } \\
\left.\text { solids ( }{ }^{\circ} \text { Brix }\right)\end{array}$ & $\mathrm{pH}$ \\
\hline CON & $83.22 \pm 0.53^{\mathrm{a} 2)}$ & $1.37 \pm 0.56^{\mathrm{e}}$ & $4.52 \pm 0.07^{\mathrm{a}}$ \\
FD & $7.45 \pm 0.40^{\mathrm{e}}$ & $6.90 \pm 0.26^{\mathrm{b}}$ & $4.47 \pm 0.02^{\mathrm{ab}}$ \\
FDS & $6.16 \pm 0.35^{\mathrm{e}}$ & $8.40 \pm 0.00^{\mathrm{a}}$ & $4.45 \pm 0.10^{\mathrm{ab}}$ \\
FDG & $5.10 \pm 0.35^{\mathrm{e}}$ & $8.47 \pm 0.12^{\mathrm{a}}$ & $4.37 \pm 0.14^{\mathrm{b}}$ \\
FDX & $3.83 \pm 0.58^{\mathrm{e}}$ & $8.10 \pm 0.20^{\mathrm{a}}$ & $4.47 \pm 0.05^{\mathrm{ab}}$ \\
HD & $54.23 \pm 1.73^{\mathrm{b}}$ & $3.70 \pm 0.17^{\mathrm{d}}$ & $4.33 \pm 0.01^{\mathrm{bc}}$ \\
HDS & $41.18 \pm 2.88^{\mathrm{c}}$ & $5.50 \pm 0.36^{\mathrm{c}}$ & $4.39 \pm 0.07^{\mathrm{ab}}$ \\
HDG & $32.27 \pm 2.71^{\mathrm{d}}$ & $5.63 \pm 0.21^{\mathrm{c}}$ & $4.21 \pm 0.08^{\mathrm{c}}$ \\
HDX & $31.65 \pm 4.36^{\mathrm{d}}$ & $5.87 \pm 0.31^{\mathrm{c}}$ & $4.38 \pm 0.04^{\mathrm{ab}}$ \\
\hline
\end{tabular}

${ }^{1)} \mathrm{CON}$, raw aronia; FD, freeze-dried; FDS, osmo-dehydrated using sucrose and freeze-dried; FDG, osmo-dehydrated using glucose and freeze-dried; FDX, osmo-dehydrated using xylitol and freeze-dried; HD, hot-air-dried; HDS, osmo-dehydrated using sucrose and hot-air-dried; HDG, osmo-dehydrated using glucose and hot-air-dried; HDX, osmo-dehydrated using xylitol and hot-air-dried.

${ }^{2)}$ Mean $\pm \mathrm{SD}(\mathrm{n}=3)$ with different lower-case letters are significantly different $(\mathrm{p}<0.05)$. 
method. As shown by Lee et al. (1990), the $\mathrm{pH}$ of glucose was 6.65 , whereas the $\mathrm{pH}$ of sucrose, sorbitol, and maltitol were $7.30,7.35$, and 7.25 , respectively.

\section{Free sugar content}

The free sugar content of the dried aronia samples is presented in Fig. 1. The FDG group had the highest glucose content $(617.34 \mathrm{mg} / \mathrm{mL}$; Fig. 1A), followed by $\mathrm{HDG}$ $(395.59 \mathrm{mg} / \mathrm{mL})$. This may be due to osmotic dehydration performed using glucose solution, because the solute (glucose) extensively infiltrated the aronia berries. In

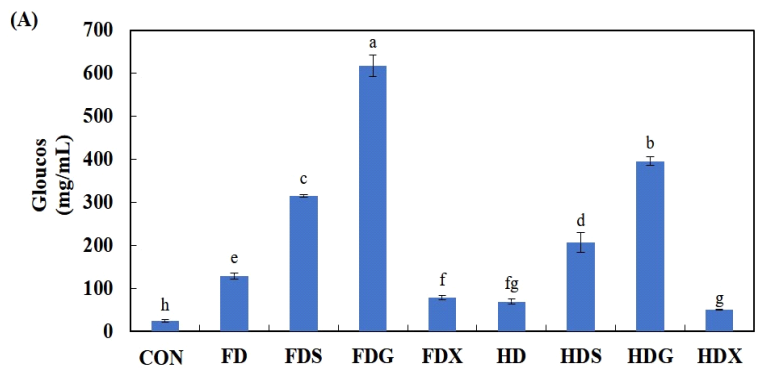

(B)

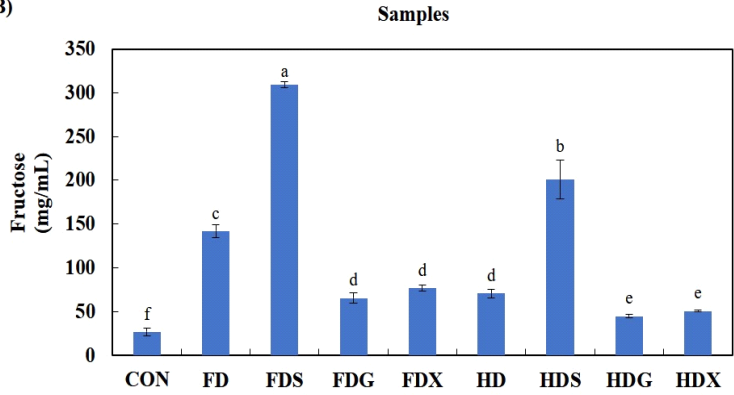

(C)

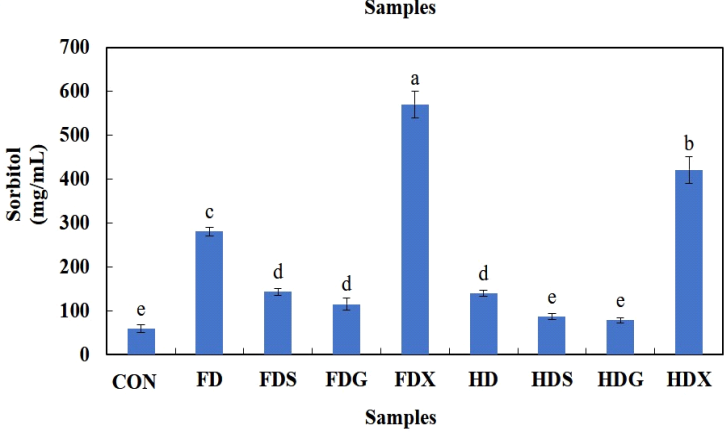

Fig. 1. Free sugar content of dried aronia berries.

(A), glucose; (B), fructose; (C), sorbitol .

${ }^{\mathrm{a}-\mathrm{h}}$ Values with different letters on the bars are significantly different $(\mathrm{p}<0.05)$.

CON, raw aronia; FD, freeze-dried; FDS, osmo-dehydrated using sucrose and freeze-dried; FDG, osmo-dehydrated using glucose and freeze-dried; FDX, osmo-dehydrated using xylitol and freeze-dried; HD, hot-air-dried; HDS, osmo-dehydrated using sucrose and hot-air-dried; HDG, osmo-dehydrated using glucose and hot-air-dried; HDX, osmo-dehydrated using xylitol and hot-air-dried. addition, the sucrose products had a higher free sugar content than the xylitol samples probably because of sucrose degradation, which causes enhanced penetration of the sugar into the aronia berries during pretreatment. Fructose content (Fig. 1B) was the highest in FDS $(308.99 \mathrm{mg} / \mathrm{mL})$, followed by HDS $(200.88 \mathrm{mg} / \mathrm{mL})$. It is believed that the sucrose molecules that penetrated aronia berries in the FDS and HDS groups were decomposed to fructose and glucose by heat-drying. Sorbitol can be detected in aronia berries. Figure 1C presents the sorbitol content, which was highest in FDX $(570.50 \mathrm{mg} / \mathrm{mL})$, followed by HDX (421.35 $\mathrm{mg} / \mathrm{mL}$ ). Xylitol and sorbitol are sugar alcohols with five and six carbons each, respectively, and share a similar structure. These results suggest that the ratio of free sugar content is affected by the pretreatment solution.

\section{Total phenolic content and antioxidant activity}

The results on TPC, AC, PC, and AA (FRAP and ABTS) are presented in Table 2. The TPC, AC, and PC displayed a similar tendency, being highest in the FD group. Among the osmo-dehydrated products, FDS and FDX had relatively high TPC, AC, PC and AA values, whereas HDX had the lowest value. The FD products had higher values for these variables than the HD products. FRAR and ABTS activity exhibited a similar tendency to the phenolic compound contents. For FD, the FRAP and ABTS values of AA were 38.70 and $46.06 \mathrm{mM} \mathrm{TE} / 100 \mathrm{~g} \mathrm{dw}$, respectively, which were the highest values observed among all the samples. Among the osmo-dehydrated products, the FRAP activities for FDS (21.12 mM TE/100 g dw) and FDX (20.91 mM TE/100 g $\mathrm{dw})$ remained higher than those of $\operatorname{HDX}(10.17 \mathrm{mM}$ TE/100 $\mathrm{g} \mathrm{dw}$ ), which had the lowest value. ABTS activity also showed that FDS (26.92 mM TE/100 $\mathrm{g} \mathrm{dw}$ ) had the third-highest value, followed by FDX, whereas HDX had the lowest value. Overall, the ABTS activity was slightly higher than the FRAP activity.

\section{Texture and color}

The texture and color of the dried aronia products are presented in Table 3. The FD samples tended to have higher texture values than the HD samples, and pretreatment with osmotic dehydration further raised these values. In the strength test, FDG had the highest strength at $22.79 \mathrm{~kg} / \mathrm{cm}^{2}$. Hardness showed the same tendency as strength, but the 
Table 2. Total phenolic content and antioxidant activities of dried aronia products

\begin{tabular}{cccccc}
\hline Sample $^{1)}$ & $\begin{array}{c}\text { Total phenolic content } \\
(\mathrm{mg} / 100 \mathrm{~g} \mathrm{dw})\end{array}$ & $\begin{array}{c}\text { Anthocyanin content } \\
(\mathrm{mg} / 100 \mathrm{~g} \mathrm{dw})\end{array}$ & $\begin{array}{c}\text { Proanthocyanidin } \\
\text { content } \\
(\mathrm{mg} / 100 \mathrm{~g} \mathrm{dw})\end{array}$ & $\begin{array}{c}\text { FRAP activity } \\
(\mathrm{mM} \mathrm{TE} / 100 \mathrm{~g} \mathrm{dw})\end{array}$ & $\begin{array}{c}\text { ABTS activity } \\
(\mathrm{mM} \text { TE/100 g dw })\end{array}$ \\
\hline CON & $4,298.99 \pm 97.81^{\mathrm{b} 2)}$ & $936.53 \pm 30.75^{\mathrm{b}}$ & $8,730.00 \pm 1020.35^{\mathrm{b}}$ & $26.37553 \pm 0.09^{\mathrm{b}}$ & $32.05871 \pm 3.55^{\mathrm{b}}$ \\
FD & $5,860.16 \pm 151.71^{\mathrm{a}}$ & $1,282.36 \pm 76.70^{\mathrm{a}}$ & $15,774.44 \pm 283.50^{\mathrm{a}}$ & $38.69542 \pm 2.36^{\mathrm{a}}$ & $46.06152 \pm 1.73^{\mathrm{a}}$ \\
FDS & $3,197.98 \pm 335.03^{\mathrm{c}}$ & $530.36 \pm 64.98^{\mathrm{c}}$ & $7,096.67 \pm 1026.32^{\mathrm{c}}$ & $21.11904 \pm 1.99^{\mathrm{c}}$ & $26.92199 \pm 3.63^{\mathrm{bc}}$ \\
FDG & $2,517.85 \pm 262.52^{\mathrm{d}}$ & $495.23 \pm 100.11^{\mathrm{c}}$ & $5,163.33 \pm 1010.50^{\mathrm{d}}$ & $17.39569 \pm 2.02^{\mathrm{cd}}$ & $20.37797 \pm 2.91^{\mathrm{de}}$ \\
FDX & $3,208.08 \pm 295.09^{\mathrm{c}}$ & $568.04 \pm 76.84^{\mathrm{c}}$ & $7,041.11 \pm 943.59^{\mathrm{c}}$ & $20.90002 \pm 2.94^{\mathrm{c}}$ & $25.30358 \pm 3.03^{\mathrm{cd}}$ \\
HD & $3,426.94 \pm 174.70^{\mathrm{c}}$ & $128.36 \pm 8.90^{\mathrm{d}}$ & $3,641.11 \pm 164.43^{\mathrm{e}}$ & $18.38128 \pm 0.59^{\mathrm{c}}$ & $24.31846 \pm 1.32^{\mathrm{cd}}$ \\
HDS & $2,463.97 \pm 333.10^{\mathrm{d}}$ & $102.04 \pm 55.85^{\mathrm{d}}$ & $2,252.22 \pm 883.39^{\mathrm{ef}}$ & $14.43892 \pm 2.96^{\mathrm{de}}$ & $17.70406 \pm 3.80^{\mathrm{ef}}$ \\
HDG & $2,300.11 \pm 76.80^{\mathrm{d}}$ & $106.10 \pm 21.43^{\mathrm{d}}$ & $2,296.67 \pm 712.59^{\mathrm{ef}}$ & $13.28906 \pm 1.83^{\mathrm{ef}}$ & $17.84479 \pm 3.39^{\mathrm{ef}}$ \\
HDX & $2,087.99 \pm 223.65^{\mathrm{d}}$ & $102.14 \pm 24.03^{\mathrm{d}}$ & $1,552.22 \pm 685.03^{\mathrm{f}}$ & $10.16802 \pm 1.46^{\mathrm{f}}$ & $13.62284 \pm 2.61^{\mathrm{f}}$ \\
\hline
\end{tabular}

${ }^{1)} \mathrm{CON}$, raw aronia; FD, freeze-dried; FDS, osmo-dehydrated using sucrose and freeze-dried; FDG, osmo-dehydrated using glucose and freeze-dried; FDX, osmo-dehydrated using xylitol and freeze-dried; HD, hot-air-dried; HDS, osmo-dehydrated using sucrose and hot-air-dried; HDG, osmo-dehydrated using glucose and hot-air-dried; HDX, osmo-dehydrated using xylitol and hot-air-dried.

${ }^{2)}$ Mean \pm SD ( $\mathrm{n}=3$ ) with different lower-case letters are significantly different $(\mathrm{p}<0.05)$.

hardness values were comparably higher than the strength values. FDG had the highest hardness valueat $288.31 \mathrm{~kg} / \mathrm{cm}^{2}$, followed by FDS at $203.06 \mathrm{~kg} / \mathrm{cm}^{2}$. Zhao et al. (2014) revealed that mangoes pretreated by osmotic dehydration with glucose solution had higher hardness than those osmo-dehydrated with sucrose or maltose solution, because the lower water content and higher freezing rate of the glucose-pretreated samples can reduce the cell structure damage, resulting in a firmer texture. The lightness $\left(\mathrm{L}^{*}\right)$ value was the highest for FD (25.28). Redness ( $\left.a^{*}\right)$ is the most important color parameter for aronia products as it greatly appeals to consumers. FDG and FDS recorded the highest $\mathrm{a}^{*}$ values among the products, which were 17.90 and 17.43, respectively. Redness $\left(\mathrm{a}^{*}\right)$ was increased by lyophilization and decreased by hot-air-drying, except for HDG. For the same drying method, aronia berries osmo-

Table 3. Texture and color values of dried aronia products

\begin{tabular}{|c|c|c|c|c|c|}
\hline Sample ${ }^{1)}$ & Strength $\left(\mathrm{kg} / \mathrm{cm}^{2}\right)$ & Hardness $\left(\mathrm{kg} / \mathrm{cm}^{2}\right)$ & $\mathrm{L}^{*}$ & $a^{*}$ & $b^{*}$ \\
\hline $\mathrm{CON}$ & $0.47 \pm 0.06^{\mathrm{D} 2)}$ & $6.87 \pm 0.06^{\mathrm{D}}$ & $20.99 \pm 4.07^{\mathrm{b} 3)}$ & $6.59 \pm 1.65^{\mathrm{c}}$ & $2.20 \pm 0.45^{\mathrm{e}}$ \\
\hline FD & $7.94 \pm 0.88^{\mathrm{C}}$ & $102.30 \pm 12.20^{\mathrm{C}}$ & $25.28 \pm 0.65^{\mathrm{a}}$ & $15.46 \pm 0.84^{\mathrm{b}}$ & $7.29 \pm 0.40^{\mathrm{a}}$ \\
\hline FDS & $17.01 \pm 3.00^{\mathrm{B}}$ & $203.06 \pm 38.01^{\mathrm{B}}$ & $17.30 \pm 0.46^{\mathrm{d}}$ & $17.43 \pm 0.76^{\mathrm{a}}$ & $6.94 \pm 0.36^{\mathrm{ab}}$ \\
\hline FDG & $22.80 \pm 5.36^{\mathrm{A}}$ & $288.31 \pm 54.08^{\mathrm{A}}$ & $21.25 \pm 0.51^{\mathrm{b}}$ & $17.90 \pm 1.00^{\mathrm{a}}$ & $6.62 \pm 0.55^{\mathrm{b}}$ \\
\hline FDX & $9.06 \pm 2.65^{\mathrm{C}}$ & $109.35 \pm 30.93^{C}$ & $20.28 \pm 0.69^{b}$ & $15.19 \pm 1.76^{\mathrm{b}}$ & $5.71 \pm 0.66^{\mathrm{c}}$ \\
\hline $\mathrm{HD}$ & $1.12 \pm 0.19^{\mathrm{D}}$ & $14.28 \pm 1.96^{\mathrm{D}}$ & $18.63 \pm 0.92^{\mathrm{c}}$ & $3.70 \pm 0.38^{\mathrm{d}}$ & $2.26 \pm 0.21^{\mathrm{e}}$ \\
\hline HDS & $1.38 \pm 0.23^{\mathrm{D}}$ & $17.35 \pm 2.30^{\mathrm{D}}$ & $20.92 \pm 1.69^{b}$ & $3.05 \pm 0.83^{\mathrm{d}}$ & $1.81 \pm 0.64^{\mathrm{f}}$ \\
\hline HDG & $1.44 \pm 0.40^{\mathrm{D}}$ & $17.56 \pm 4.43^{\mathrm{D}}$ & $19.85 \pm 2.03^{\mathrm{bc}}$ & $6.59 \pm 1.54^{\mathrm{c}}$ & $3.53 \pm 0.64^{\mathrm{d}}$ \\
\hline HDX & $1.63 \pm 0.41^{\mathrm{D}}$ & $20.53 \pm 4.86^{\mathrm{D}}$ & $21.19 \pm 1.05^{\mathrm{b}}$ & $1.97 \pm 0.23^{\mathrm{e}}$ & $1.26 \pm 0.18^{\mathrm{g}}$ \\
\hline
\end{tabular}

${ }^{15} \mathrm{CON}$, raw aronia; FD, freeze-dried; FDS, osmo-dehydrated using sucrose and freeze-dried; FDG, osmo-dehydrated using glucose and freeze-dried; FDX, osmo-dehydrated using xylitol and freeze-dried; HD, hot-air-dried; HDS, osmo-dehydrated using sucrose and hot-air-dried; HDG, osmo-dehydrated using glucose and hot-air-dried; HDX, osmo-dehydrated using xylitol and hot-air-dried.

${ }^{2)}$ Mean \pm SD $(n=5)$ with different upper-case letters are significantly different $(\mathrm{p}<0.05)$ for strength and hardness values.

${ }^{3)}$ Mean \pm SD $(n=15)$ with different lower-case letters are significantly different $(\mathrm{p}<0.05)$ for $\mathrm{L}^{*}, \mathrm{a}^{*}$, and $\mathrm{b}^{*}$ values. 
dehydrated with glucose solution presented a higher $\mathrm{a}^{*}$ value, whereas xylitol solution tended toward a lower $\mathrm{a}^{*}$ value. In the case of yellowness $\left(b^{*}\right)$, the FD samples had greater yellow intensity than CON and HD samples. FD had the highest yellowness at $7.29\left(b^{*}\right)$. When samples that underwent the same drying process but different pretreatments were compared, FDX and HDX showed the lowest $\mathrm{b}^{*}$ values at 5.71 and 1.26 , respectively. This is because polyols such as xylitol do not caramelize, in contrast to other sweeteners (Bar, 1985).

\section{Sensory evaluation}

The sensory test scores are shown in Table 4. In terms of appearance, the HD samples showed relatively low preference, which may be attributed to their shattered appearance caused by hot-air-drying. In addition, HDG received the lowest score for color. There was no noticeable difference in texture, but FDX scored the lowest with 3.53 points. Unlike the other freeze-dried products that had a crispy texture, FDX was soft and sticky, as also evidenced by the relatively low instrumentally determined strength and hardness (Table 4), as well as chewiness. Chewiness score was highest for FDG with 5.20 points, followed by FDS, which could be a reflection of the relatively high strength and hardness values obtained for these products, as shown in Table 4. According to Joo et al. (2013), acorn powder cookies with higher hardness had greater texture sensory preference. Regarding sweetness, FDS had the highest acceptability, whereas HD (2.60 points) was commercially unviable. Because of its perceived sourness, $\mathrm{CON}$ is also commercial unviable. Astringency was most severe for HD (4.93 points). For the overall preference, FDS scored the highest with 5.13 points, followed by FDG with 4.80 points. In comparison, $\mathrm{CON}, \mathrm{FD}$, and $\mathrm{HD}$ scored low, possibly because these samples did not undergo pretreatment. Therefore, osmotic dehydration, especially using sucrose or glucose solution, may increase the acceptability of dried aronia products, whereas non-pretreated products were considered commercially unacceptable.

In conclusion, based on the results of MC and TSS, it is recommended that freeze-drying should be used rather than hot-air-drying to prepare dried aronia products. Phenolic compound contents and $\mathrm{AA}$ were higher in the order of $\mathrm{FD}$, CON, and FDS or FDX. The sensory test showed that FDS scored the highest value of sweetness and overall preference, whereas $\mathrm{CON}, \mathrm{FD}$, and $\mathrm{HD}$ are considered of no commercial value. FDG and FDS showed high texture and redness values. Therefore, FDS, which has high scores in sensory tests and physical property values, with relatively low reduction of phenolic contents and AA, seems to be the most appropriate preservation method to obtain new dried aronia products.

Table 4. Sensory evaluation scores of dried aronia berries

\begin{tabular}{|c|c|c|c|c|c|c|c|c|}
\hline Sample & Appearance & Color & Texture & Chewiness & Sweetness & Sourness & Astringency & $\begin{array}{c}\text { Overall } \\
\text { preference }\end{array}$ \\
\hline $\mathrm{CON}^{1)}$ & $5.87 \pm 0.99^{\mathrm{a} 2)}$ & $5.93 \pm 0.88^{\mathrm{a}}$ & $3.93 \pm 1.87^{\mathrm{a}}$ & $4.00 \pm 1.60^{\mathrm{abc}}$ & $3.07 \pm 1.49^{\mathrm{bc}}$ & $2.93 \pm 1.94^{\mathrm{a}}$ & $3.60 \pm 1.30^{\mathrm{ab}}$ & $4.00 \pm 1.77^{\mathrm{a}}$ \\
\hline FD & $5.67 \pm 0.72^{\mathrm{ab}}$ & $5.47 \pm 1.13^{\mathrm{ab}}$ & $4.13 \pm 1.36^{\mathrm{a}}$ & $4.27 \pm 1.44^{\mathrm{abc}}$ & $3.33 \pm 1.63^{\mathrm{bc}}$ & $3.40 \pm 1.96^{\mathrm{a}}$ & $4.87 \pm 1.60^{\mathrm{ab}}$ & $4.13 \pm 1.68^{\mathrm{a}}$ \\
\hline FDS & $4.93 \pm 1.03^{\mathrm{bc}}$ & $5.40 \pm 1.40^{\mathrm{ab}}$ & $4.27 \pm 1.49^{\mathrm{a}}$ & $5.07 \pm 1.62^{\mathrm{ab}}$ & $5.07 \pm 1.03^{\mathrm{a}}$ & $3.00 \pm 1.93^{\mathrm{a}}$ & $4.27 \pm 2.12^{\mathrm{ab}}$ & $5.13 \pm 1.64^{\mathrm{a}}$ \\
\hline FDG & $5.07 \pm 1.03^{\mathrm{abc}}$ & $5.67 \pm 1.29^{\mathrm{ab}}$ & $4.20 \pm 1.15^{\mathrm{a}}$ & $5.20 \pm 1.66^{\mathrm{a}}$ & $4.80 \pm 1.78^{\mathrm{a}}$ & $3.33 \pm 2.06^{\mathrm{a}}$ & $3.73 \pm 1.10^{\mathrm{ab}}$ & $4.80 \pm 1.52^{\mathrm{a}}$ \\
\hline FDX & $5.40 \pm 1.06^{\mathrm{ab}}$ & $5.60 \pm 1.24^{\mathrm{ab}}$ & $3.53 \pm 1.60^{\mathrm{a}}$ & $3.87 \pm 1.81^{\mathrm{bc}}$ & $4.67 \pm 1.84^{\mathrm{a}}$ & $3.27 \pm 2.15^{\mathrm{a}}$ & $3.87 \pm 1.92^{\mathrm{ab}}$ & $4.47 \pm 1.73^{\mathrm{a}}$ \\
\hline $\mathrm{HD}$ & $3.93 \pm 0.96^{\mathrm{d}}$ & $4.93 \pm 1.33^{\mathrm{ab}}$ & $3.67 \pm 1.59^{\mathrm{a}}$ & $3.73 \pm 1.62^{\mathrm{c}}$ & $2.60 \pm 1.45^{\mathrm{c}}$ & $3.67 \pm 1.40^{\mathrm{a}}$ & $4.93 \pm 1.67^{\mathrm{a}}$ & $3.87 \pm 1.06^{\mathrm{a}}$ \\
\hline HDS & $4.27 \pm 1.26^{\mathrm{cd}}$ & $5.20 \pm 1.61^{\mathrm{ab}}$ & $4.07 \pm 1.75^{\mathrm{a}}$ & $4.40 \pm 1.55^{\mathrm{abc}}$ & $4.67 \pm 1.50^{\mathrm{a}}$ & $3.27 \pm 1.67^{\mathrm{a}}$ & $3.93 \pm 1.71^{\mathrm{ab}}$ & $4.40 \pm 1.35^{\mathrm{a}}$ \\
\hline HDG & $3.80 \pm 1.26^{\mathrm{d}}$ & $4.67 \pm 1.63^{b}$ & $4.13 \pm 1.46^{\mathrm{a}}$ & $4.13 \pm 1.36^{\mathrm{abc}}$ & $4.20 \pm 1.90^{\mathrm{ab}}$ & $3.33 \pm 1.80^{\mathrm{a}}$ & $4.13 \pm 1.51^{\mathrm{ab}}$ & $4.47 \pm 1.25^{\mathrm{a}}$ \\
\hline HDX & $4.40 \pm 1.45^{\mathrm{cd}}$ & $5.27 \pm 1.58^{\mathrm{ab}}$ & $4.00 \pm 1.60^{\mathrm{a}}$ & $4.07 \pm 1.53^{\mathrm{abc}}$ & $4.00 \pm 1.73^{\mathrm{ab}}$ & $3.20 \pm 1.90^{\mathrm{a}}$ & $3.53 \pm 1.55^{\mathrm{b}}$ & $4.33 \pm 1.29^{\mathrm{a}}$ \\
\hline
\end{tabular}

${ }^{1)} \mathrm{CON}$, raw aronia; FD, freeze-dried; FDS, osmo-dehydrated using sucrose and freeze-dried; FDG, osmo-dehydrated using glucose and freeze-dried; FDX, osmo-dehydrated using xylitol and freeze-dried; HD, hot-air-dried; HDS, osmo-dehydrated using sucrose and hot-air-dried; HDG, osmo-dehydrated using glucose and hot-air-dried; HDX, osmo-dehydrated using xylitol and hot-air-dried.

${ }^{2)}$ Mean \pm SD $(n=15)$ with different superscript are significantly different $(\mathrm{p}<0.05)$. 


\section{Conflict of interest}

None of the authors of this study has any financial interest or conflict with industries or parties.

\section{ORCID}

Suin Bae https://orcid.org/0000-0002-1561-5492 Kwang-deog Moon

https://orcid.org/0000-0001-5277-3345

\section{References}

Ahmed I, Qazi IM, Jamal S. Developments in osmotic dehydration technique for the preservation of fruits and vegetables. Innovative Food Sci Emerging Technol, 34, 29-43 (2016)

Bar A. Xylitol. In: Alternative Sweeteners, Gelardi RC (Editor), L O'Brien Nabors, Marcel Dekker, Inc. New York NY, USA, p 153-160 (1985)

Benvenuti S, Pellati F, Melegari M, Bertelli D. Polyphenols, anthocyanins ascorbic acid, and radical scavenging activity of Rubus, Ribes, and Aronia. J Food Sci, 69, 164-169 (2004)

Benzie IFF, Strain JJ. The ferric reducing ability of plasma (FRAP) as a measure of "antioxidant power": The FRAP assay. Anal Biochem, 239, $70-76$ (1996)

Broadhurst RB, Jones WT. Analysis of condensed tannins using acidified vanillin. J Sci Fd Agric, 29, 788-794 (1978)

Choi KH, Oh HJ, Jeong YJ, Lim EJ, Han JS, Kim JH, Kim OY, Lee HS. Physico-chemical analysis and antioxidant activities of Korea Aronia melanocarpa. J Korean Soc Food Sci Nutr, 44, 1165-1171 (2015)

Dev SRS, Raghavan VGS. Advancements in drying techniques for food, fiber, and fuel. Drying Technol, 30, 1147-1159 (2012)

Giusti MM, Wrolstad RE. Characterization and measurement of anthocyanins by UV-visible spectroscopy. In: Current Protocols in Food Analytical Chemistry, John Wiley and Sons Inc, Hoboken, NJ, USA (2001)

Hardin JW. The enigmatic chokeberries (Aronia, Rosaceae). Bull Torrey Bot Club, 100, 178-184 (1973)
Hwang ES, Lee YJ. Quality characteristics and antioxidant activities of Yanggaeng with aronia juice. J Korean Soc Food Sci Nutr, 42, 1220-1226 (2013)

Joo SY, Kim OS, Jeon HK, Choi HY. Antioxidant activity and quality characteristics of cookies prepared with acorn (Quercus species) powder. Korean J Food Cook Sci, 29, 177-184 (2013)

Kim DH, Cho JS, Park JH, Kim JH, Moon KD. Quality characteristics of steamed rice cake with Schisandra chinensis powder or extract added prior to storage. Korean J Food Preserv, 23, 923-930 (2016)

Lee CH, Souane M, Lee HD, Kim SY. Studies of the functional properties of sugar derivative sweeteners. Korean J Dietary Culture, 5, 431-436 (1990)

Lewicki PP, Lenart A. Osmotic dehydration of fruits and vegetables. In: Handbook of Industrial Drying, 4th ed, Mujumdar AS (Editor), CRC Press, Boca Raton, FL, USA, p 665-681 (2006)

Mishra BB, Gautam S, Chander R, Sharma A. Characterization of nutritional, organoleptic and functional properties of intermediate moisture shelf stable ready-to-eat Carica papaya cubes. Food Biosci, 10, 69-79 (2015)

Oszmianski J, Wojdylo A. Aronia melanocarpa phenolics and their antioxidant activity. Eur Food Res Technol, 221, 809-813 (2005)

Re R, Pellegrini N, Proteggente A, Pannala A, Yang M, Rice-Evans C. Antioxidant activity applying an improved ABTS radical cation decolorization assay. Free Radicals Biol Med, 26, 1231-1237 (1999)

Sidor A, Drozdzynska A, Gramza-Michalowska AG. Black chokeberry (Aronia melanocarpa) and its products as potential health-promoting factors - An overview. Trends Food Sci Technol, 89, 45-60 (2019)

Soares S, Brandao E, Mateus N, de Freitas V. Sensorial properties of red wine polyphenols: Astringency and bitterness. Crit Rev Food Sci Nutr, 57, 937-948 (2017)

Xie DY, Dixon RA. Proanthocyanidin biosynthesis-still more questions than answers?. Phytochemistry, 66, 2127-2144 (2005)

Zhao JH, Hu R, Xiao HW, Yang Y, Liu F, Gan ZL, Ni YY. Osmotic dehydration pretreatment for improving the quality attributes of frozen mango: Effect of different osmotic solutes and concentrations on the samples. Int J Food Sci Technol, 49, 960-968 (2014) 